\author{
Wojciech Augustyniak \\ dr nauk ekonomicznych \\ Uniwersytet Ekonomiczny w Poznaniu \\ Katedra Mikroekonomii \\ w.augustyniak@ue.poznan.pl
}

DOI: $10.35117 /$ A_ENG_17_12_03

\title{
Analysis of break-even points of Polish regional airports
}

\begin{abstract}
The problematic nature of the high costs of building terrestrial aviation infrastructure does not end after the planning phase and the construction of new airspace. After the infrastructure has been commissioned, the cost of its depreciation and maintenance over the years represents a significant contribution to the cost of operating the airport. The high share of fixed costs is a direct reason for strong leverage. As a result, it is imperative to provide external financing to young airports at an early stage of their development. Owners of companies managing the above-mentioned infrastructure should be vividly concerned about the earliest possible break-even point, and consequently, the burden of direct subsidizing aviation activities in the region.

The purpose of this article is to analyze the profitability thresholds at Polish regional airports as a means to discuss possible minimum volumes and revenues that emerging airports need to achieve as they do not generate losses. The main research method is a tool based on regression functions.
\end{abstract}

Keywords: Airports; Profitability; Break-even point

\section{Introduction}

During industry meetings and scientific conferences devoted to the construction of new airports, the question about financial forecasts of two types often arises. The first of them are questions about the economic effects generated by the newly created airport. Direct, indirect, stimulated and induced effects are examined by models of inputs and effects [6], costs and benefits [7] and catalytic models [8].The answer to the second type of questions seems somewhat simpler, i.e. "When will the airport stop generating losses?" or more precisely, "What minimum passenger traffic will be able to reach the break-even point of the management company?" Both questions seem to interest most owners of these entities, which in the Polish realities are most often local governments at the level of the commune and province in cooperation with the State Enterprise "Porty Lotnicze".

In the scientific literature, there are quantitative break-even points in the area of 1 million passengers served annually (PAX) for larger airports and about 0.5 million PAX for local airports. An example of such a study is the study of Dr. Adler [2], whose team examined 85 European regional airports with traffic below 1.5 million PAX in the period 2002-2009. A break-even point for traffic of 0.464 million PAX was obtained and it was shown that due to increasing cost burdens (e.g. due to tightened safety regulations), the threshold increased by $100 \%$ over the decade.

Another analysis of this type is the work of Bubalo [2], in which the author compares 210 European airports of different sizes during the period (2002-2010). Regression analyzes have shown that airports usually reach the break-even point at the EBIT level after exceeding about 1 million PAX. The analysis of empirical data also showed that financial results significantly higher than zero are obtained only by enterprises with at least PAX 2 million traffic. The author also indicates that the use of average measures may be harmful to 
extremely small and extremely large entities discussed in these analyzes. In this case, he proposes to use the Profitability Envelope algorithm, which sets the benchmark for individual airports from other entities of similar size.

\section{Data}

The study used data on realized passenger traffic on an annual basis available on the websites of the Civil Aviation Office [5] and from financial data provided in the Polish Monitor B, and published in the Emerging Markets Information Services database [4]. The built database had 136 observations gathering information on passenger traffic, sales revenues and net profit in 11 Polish regional airports in the years:

- Kraków-Balice Airport (KRK): 2000-2015

- Gdańsk-Rębiechowo Airport (GDN): 2000-2015

- Katowice International Airport in Pyrzowice (KTW): 2000-2015

- Warsaw-Modlin Airport (WMI): 2012-2015

- Wrocław-Strachowice Airport (WRO): 2000-2015

- Poznań-Ławica Airport (POZ): 2000-2015

- Rzeszów-Jasionka Airport (RZE): 2009-2015

- Szczecin-Goleniów (SSZ) airport: 2001-2015

- Lublin Airport (LUZ): 2012-2015

- Bydgoszcz Airport (BZG): 2000-2015

- $\quad$ Łódź Airport (LCJ): 2004-2015

The study did not include the Warsaw Chopin Airport for three reasons. The first one is a different character of the activity, which is based largely on traditional carriers, transfer passengers, and the hub-and-spoke system. The second reason is a much larger scale of activity that could disturb the significance of regression equations. The third reason is the inability to obtain financial data. According to the information obtained by correspondence from the P.P. "Porty Lotnicze", the company does not keep separate financial books for the abovementioned airports.

Chart 1 presents the net profit/loss in the analyzed companies in the last 4 years of the analysis. You can read the confirmation of Bubalo's thesis. Large airports with traffic exceeding 2 million PAX, ie Kraków's KRK, KTW Katowice and Gdańsk GDN, actually record relatively high net profits, ie in the PLN 10-50 $\mathrm{mn}$ range. The financial result of medium ports, i.e. the PAX traffic volume, 1-2 million oscillates around the break-even point, and smaller ports usually record a loss of up to -50 million (Lodz LCJ in 2015).

\section{Regression results}

In order to calculate quantitative and valuable profitability thresholds, two regression analyzes were carried out according to the scheme recommended by Aczel [1]. Net profits/losses were explained respectively: annual number of passengers served (chart 2) and sales revenues (chart 3). In both cases, results with high statistical significance were obtained, ie with the parameter value $\mathrm{p}<0.0001^{* * *}$.

The function was obtained for the first dependency:

Profit_net $=0,0129 *$ PAX -12800

The quantitative break-even point, understood as the zero point of the above function, is obtained for the annual number of passengers served PAX $\mathrm{BEP}_{\mathrm{BEP}}=992248$.

The second dependence has been described by the function:

Profit_net $=0,263 *$ REV -12400

The value break-even point understood as the zero point of the above function is obtained for the sales value $\mathrm{REV}_{\mathrm{BEP}}=47148288[\mathrm{pln}]$. Dokładne the results of both analyzes are presented in tables $\mathbf{1}$ and $\mathbf{2}$. 
Tab. 1. KMNK estimation, used observations 1-136, dependent variable (Y): Profit_net, independent variable PAX (number of passengers served) Source: own study

\begin{tabular}{|c|c|c|c|c|c|c|c|}
\hline & Factor & \multicolumn{2}{|c|}{$\begin{array}{l}\text { Standard } \\
\text { error }\end{array}$} & Student's $t$ & \multicolumn{3}{|c|}{$p$ value } \\
\hline Const & $-12834,1$ & \multicolumn{2}{|c|}{1477,77} & $-8,685$ & \multicolumn{2}{|c|}{$<0,0001$} & $* * *$ \\
\hline PAX & 0,0128747 & 0,00 & 0185 & 12,85 & & & $* * *$ \\
\hline \multicolumn{2}{|c|}{$\begin{array}{l}\text { The arithmetic mean of } \\
\text { the dependent variable }\end{array}$} & 558,8729 & \multicolumn{3}{|c|}{$\begin{array}{l}\text { Standard deviation of a } \\
\text { dependent variable }\end{array}$} & \multicolumn{2}{|c|}{18187,74} \\
\hline $\begin{array}{l}\text { The sum of residual } \\
\text { squares }\end{array}$ & & $2,00 \mathrm{e}+10$ & \multicolumn{3}{|c|}{$\begin{array}{l}\text { Standard error of } \\
\text { residues }\end{array}$} & \multicolumn{2}{|c|}{12218,11} \\
\hline $\begin{array}{l}\text { Factor determining R- } \\
\text { square }\end{array}$ & \multicolumn{2}{|c|}{0,552058} & \multicolumn{3}{|c|}{ Adjusted R-square } & \multicolumn{2}{|c|}{0,548715} \\
\hline $\mathrm{F}(1,134)$ & \multicolumn{2}{|c|}{165,1459} & \multicolumn{3}{|c|}{ The $p$ value for the $F$ test } & \multicolumn{2}{|c|}{$3,94 \mathrm{e}-25$} \\
\hline Logarithm of credibility & \multicolumn{2}{|c|}{$-1471,820$} & \multicolumn{3}{|c|}{ Akaike's crit. inform. } & \multicolumn{2}{|c|}{2947,640} \\
\hline Schwarz's bayes. crit. & \multicolumn{2}{|c|}{2953,465} & \multicolumn{3}{|c|}{ Hannan-Quinn's crit. } & \multicolumn{2}{|c|}{2950,007} \\
\hline
\end{tabular}

Tab. 2. KMNK estimation, used observations 1-136, dependent variable (Y): Profit_net, independent variable REV (sales revenue in thousands PLN) Source: own study

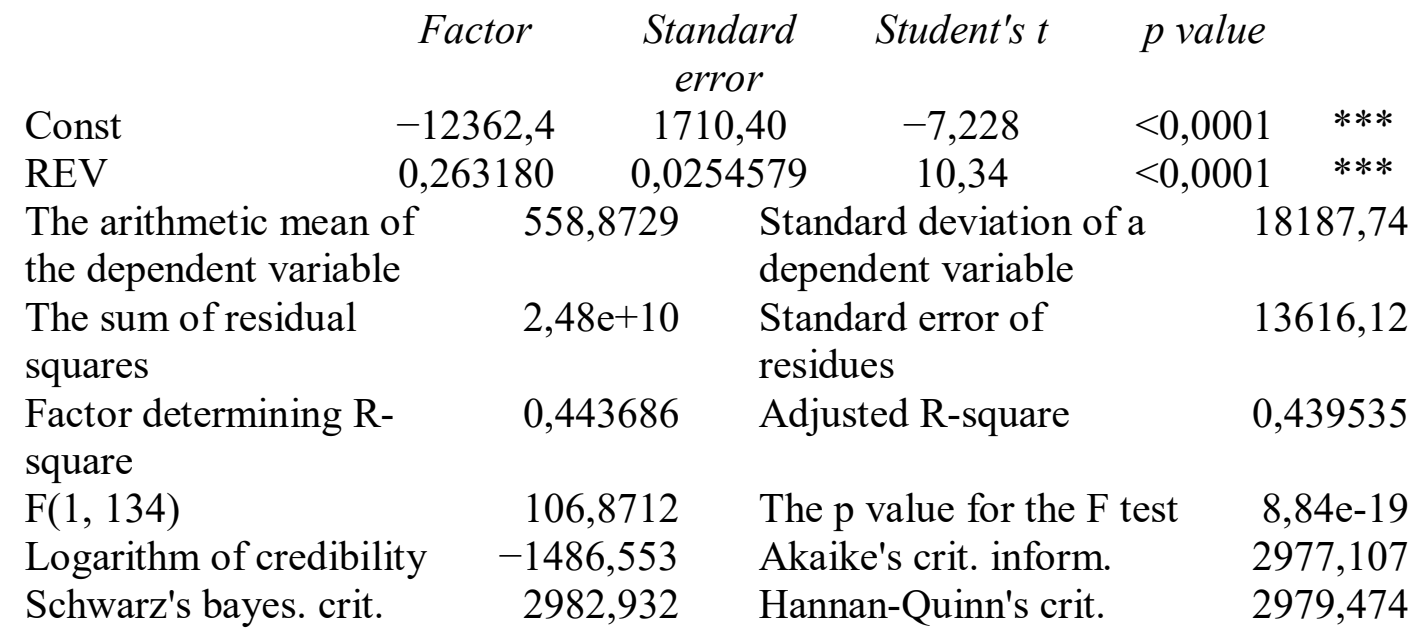

It should be remembered that the results obtained indicate the theoretical and averaged breakeven levels. The constant residual component is, in fact, the consequence of the assumption of constant fixed costs and constant dynamics of variable costs. In fact, in the longer term, these costs grow by leaps and bounds.

Despite its theoretical nature, a linear profit function can be used to identify those areas in which the above-mentioned values increase by leaps and bounds. For this purpose, the Profitability Envelope algorithm can be used, which, despite the repeatedly high theoreticality, allows showing the areas of abrupt increase in the explained variable. The method consists of dividing the population into subgroups. In each of them, the observation with the highest profit becomes a relative benchmark for the rest. In subsequent iterations, increasing the value of the explanatory variable, the script draws a new group after finding an observation with a function value higher than the previous benchmark. The method code in the $\mathrm{R}$ language is presented in table 3. Graphical results of the script are marked in green on graphs $\mathbf{1}$ and $\mathbf{2}$. 
Tab. 3 Algorithm of the Profitability Envelope method. Source: own study based on [3]

\begin{tabular}{|ll|}
\hline $\mathrm{i}=1$ to $\mathrm{n}$ & \# $\mathrm{n}=$ number of observations \\
$\mathrm{PAX}_{\mathrm{i}}<\mathrm{PAX}_{\mathrm{i}}+1<\ldots<\mathrm{PAX}_{\mathrm{n}}$ & \# Sorting the PAX column ascending. \\
Envelope $_{\mathrm{i}}=$ Profit_net $_{\mathrm{i}}$ & \# Initialization of the first data point in \\
& \# 'Net profit'; $\mathrm{i}=1$. \\
For $\mathrm{i}$ to $\mathrm{n} \geq 2$, & \# Starting from the second data point \\
Envelope $\mathrm{i}+1=$ & \# a new observation is becoming an envelope \\
& \# if its value is greater than the last \# \\
& benchmark in 'Profit_net' \\
Loop: & \\
If Profit_net $\mathrm{i}+1>$ Envelope $_{\mathrm{i}}$ & \\
Then Profit_net $\mathrm{i}+1$ & \\
Else Envelope &
\end{tabular}

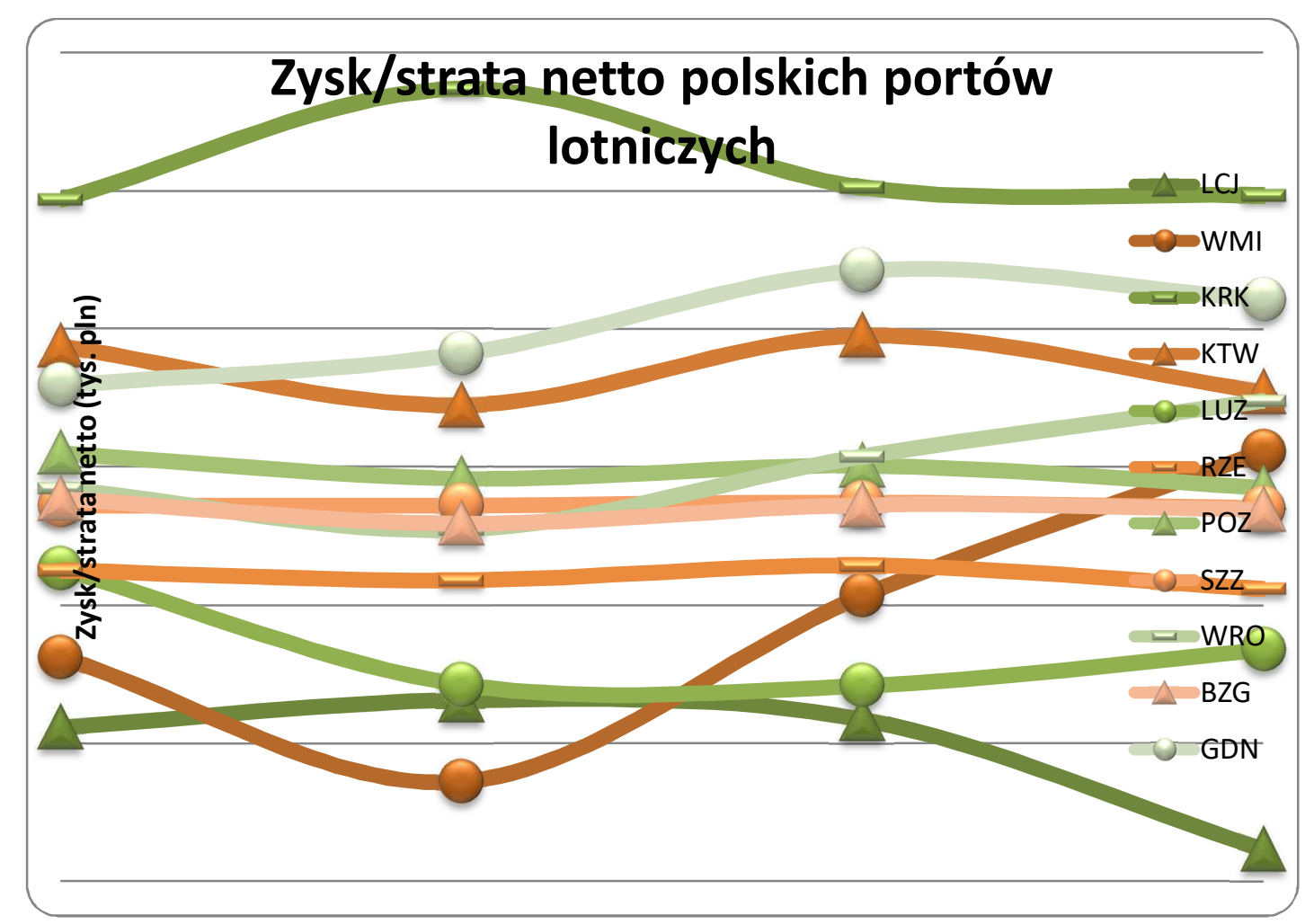

1. Profit / net loss of Polish airports in 2012-2015 in thousand PLN. Source: own study 


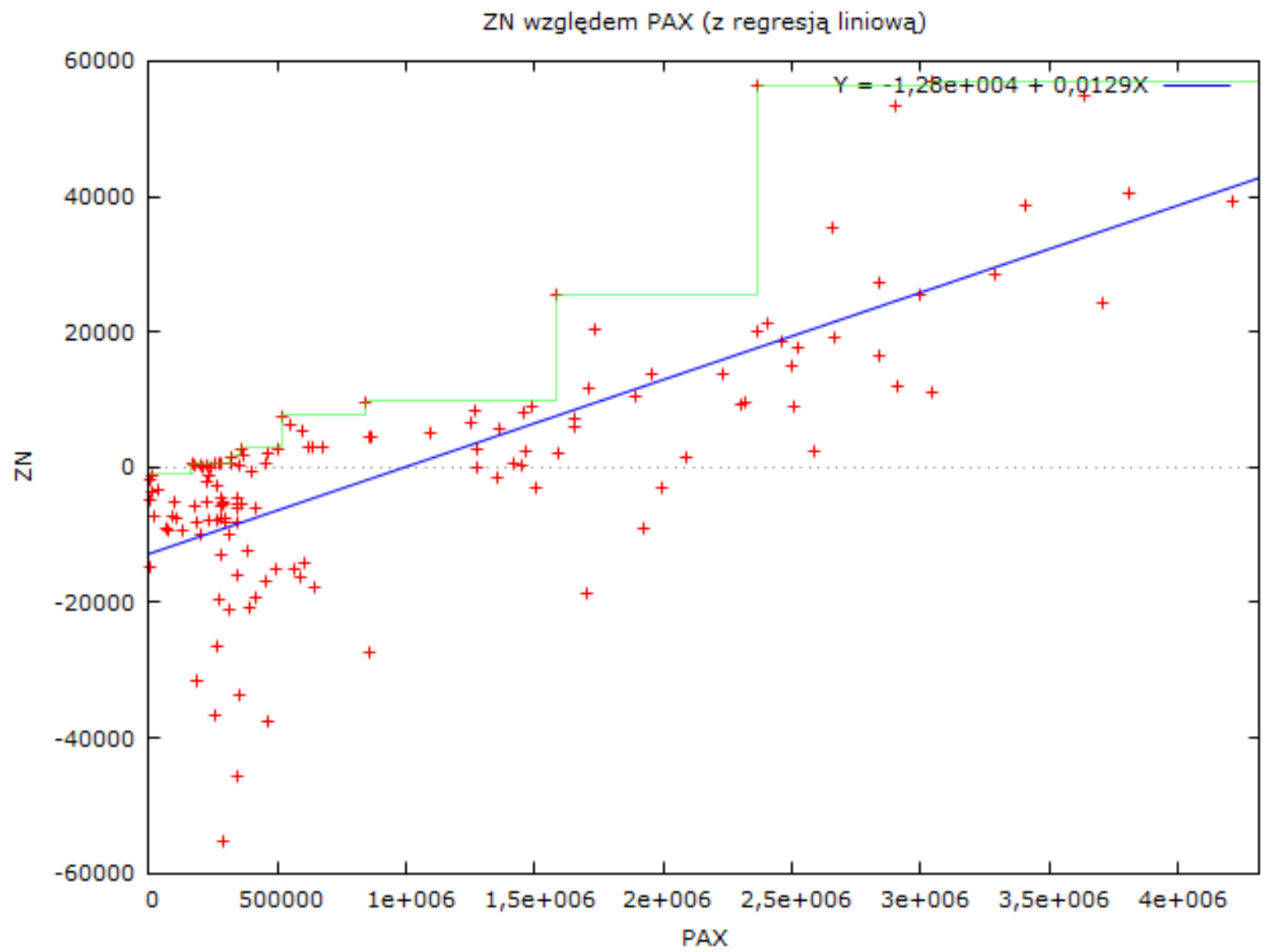

2. Profit / net loss (thousand PLN ) compared to the annual number of passengers served (PAX) Source: own study

The Profitability Envelope method allowed to designate three groups of airports established by PAX size:

- small: with annual passenger transport below 0.6 million PAX

- average: with annual passenger transport 0.6-1.6 million PAX

- large: with annual passenger transport of over 1.6 million PAX

Benchmarks for small airports turned out to be airports in Poznan and Katowice, which at the beginning of the 21 st century recorded positive net profits of up to PLN 0.5 million. For medium-sized enterprises, the airport in Wrocław became the model with data from 2010, when net profits were achieved at the level of PLN $7 \mathrm{mn}$. In turn, for large airports, the model designated the airport in Krakow in 2006-2008 with net profits exceeding PLN 50 million. 


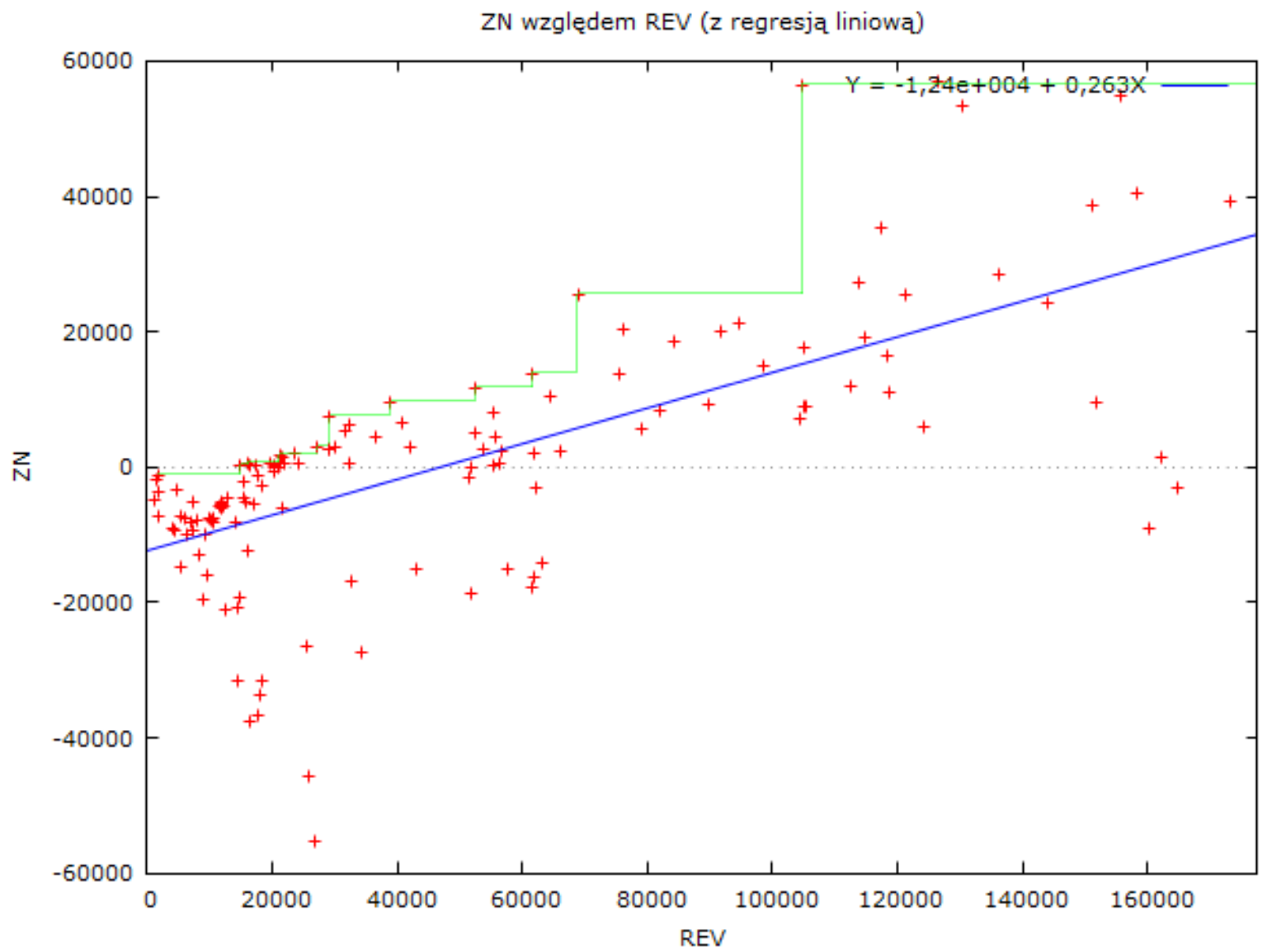

3. Profit / net loss (thousand PLN) versus annual sales (REV) (thousand PLN) Source: own study

\section{Summary}

The analysis shows that the quantitative break-even point of Polish airports does not differ from the average values calculated for their European counterparts. In both cases, profits appear on average after exceeding 1 million passengers per year, which corresponds to a minimum income of PLN $47 \mathrm{mn}$ on the Polish market. The Profitability Envelope algorithm has also shown that it is possible to achieve profitability earlier. Then small airports (PAX $<0.6$ million) may strive to achieve benchmark profits, ie $0.2-0.5$ million PLN. Mediumsized airports $(0.6$ million $<\mathrm{PAX}<1.6$ million $)$ can compare their results with a profit of PLN 7 million. Benchmark for large, regional airports (PAX $>1.6$ million) is a profit of PLN 50 million.

For further analysis, the author recommends the use of the above results to create scenarios of changes in the company's operating costs, e.g. through the analysis of benefits and costs (cost-benefit, CBA) in the field of, among others the level of airport charges, in order to check the sensitivity of individual costs to the relative result of a given entity in relation to the benchmark.

The work was created as a result of the research project No. 2015/17 / D / HS4 / 00363 financed from the funds of the National Science Center

\section{Source materials}

[1] Aczel A., Statystyka w zarządzaniu, Wydawnictwo Naukowe PWN, Warszawa, 1, 2011, 456-505 
[2] Adler N., Ülkü T., Yazhemsky E., Small regional airport sustainability: Lessons from benchmarking, Journal of Air Transport Management, 33 (2013), 22-31

[3] Bubalo B., Benchmarking selected European Airports by their Profitability Envelope a Break-Even Analysis, German Aviation Research Society, German Aviation Benchmaring Final Project Meeting, Berlin, June 20th 2012

[4] https://www.emis.com/, dostęp: 10.10.2017

[5] http://www.ulc.gov.pl/pl/publikacje/statystyki-i-analizy, dostęp: 10.10.2017

[6] Huderek-Glapska S., Inchausti-Sintes F., Njoya E., Modeling the impact of air transport on the economy - practices, problems and prospects, LogForum, 2016, 12 (1), 47-61

[7] Huderek-Glapska S., Oddziaływanie portu lotniczego na gospodarkę regionu, Przegląd Komunikacyjny, $\mathrm{Nr}$ 2, 2012, ss. 20-26

[8] Huderek-Glapska S., Wpływ portu lotniczego na rozwój gospodarki regionu, Rozprawa doktorska. Uniwersytet Ekonomiczny w Poznaniu, Poznań 2011 